\title{
PREVALENCE OF GASTRO-INTESTINAL PARASITES OF RHESUS MACAQUE (MACACA MULATTA ZIMMERMANN, 1780) AND HANUMAN LANGUR (SEMNOPITHECUS ENTELLUS DUFRESNE, 1797) IN DEVGHAT, CHITWAN, NEPAL
}

\section{Pujan Prasad Adhikari and Pitambar Dhakal}

Journal of Institute of Science and Technology

Volume 22, Issue 2, January 2018

ISSN: 2469-9062 (print), 2467-9240 (e)

Editors:

Prof. Dr. Kumar Sapkota

Prof. Dr. Armila Rajbhandari

Assoc. Prof. Dr. Gopi Chandra Kaphle

Mrs. Reshma Tuladhar

JIST, 22 (2): 12-18 (2018)

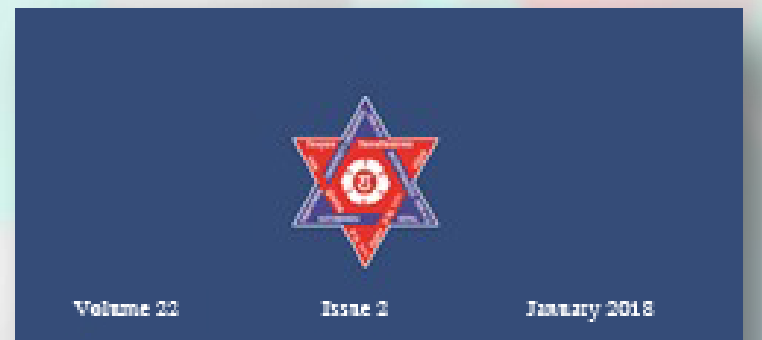

JOURNAL OF INSTITUTE OF

SCIENCE AND TECHNOLOGY

Published by:

Institute of Science and Technology

Tribhuvan University

Kirtipur, Kathmandu, Nepal 


\title{
PREVALENCE OF GASTRO-INTESTINAL PARASITES OF RHESUS MACAQUE (MACACA MULATTA ZIMMERMANN, 1780) AND HANUMAN LANGUR (SEMNOPITHECUS ENTELLUS DUFRESNE, 1797) IN DEVGHAT, CHITWAN, NEPAL
}

\author{
Pujan Prasad Adhikari and Pitambar Dhakal" \\ Central Department of Zoology, Tribhuvan University, Kirtipur, Kathmandu, Nepal \\ Corresponding E-mail: dhakal.ohm@gmail.com
}

Received: 11 April, 2017; Revised: 5 September, 2017; Accepted: 8 September, 2017

\begin{abstract}
The present investigation was undertaken to study the prevalence of gastrointestinal parasites in Rhesus Macaque and Hanuman Langur at Devghat, Chitwan. Altogether 93 fresh faecal samples were collected from Rhesus Macaque belonging to five troops and Hanuman Langur of two troops. About $10 \mathrm{gm}$ of faecal material was collected in sterile vials with $2.5 \%$ potassium dichromate solution. These samples were examined microscopically by faecal concentration methods viz. floatation technique and sedimentation technique. Out of 93 samples, 69 (74.20\%) were found positive for at least one parasite. Prevalence of helminth and protozoan parasites was $52.68 \%$ and $40.86 \%$ respectively. Altogether, 10 species of parasites including seven helminth and three protozoa were identified based on morphological characteristics of their eggs and cysts under light microscopy. The most commonly detected parasites were Balantidium coli (27.95\%) followed by Eimeria sp. (16.12\%), Entamoeba sp. (13.97\%), Trichuris sp. (23.65\%), Ascaris sp. (11.82\%), Strongyloides sp. (10.75\%), Oesophagostomum sp. (5.37\%), Hookworm sp. (3.22\%), Trichostrongylus sp. (3.22\%) and Hymenolepis sp. (1.07\%). Unidentified larvae of nematode which account for $6.45 \%$ of total samples were also recorded. Single, double, triple and multiple species of parasites were found in $36.55 \%, 29.03 \%, 6.45 \%$ and $2.15 \%$ samples respectively.
\end{abstract}

Keywords: Floatation and sedimentation technique, Gastro-intestinal parasite, Hanuman Langur, Macaque, Protozoan parasites.

\section{INTRODUCTION}

Rhesus Macaque and Hanuman Langur are diurnal animals which exist in both arboreal and terrestrial conditions. Hanuman Langurs are timid and less aggressive to human beings and hence are mostly arboreal in comparison to Rhesus Macaque (Chalise et al., 2005; Gewali, 2013). They are leafivorous and insectivorous. Rhesus Macaques are adjustable to environment of human beings and successfully exist in village, cities and towns but Hanuman Langurs are found in mixed deciduous and evergreen forest (Chalise et al., 2005; Gewali, 2013).

There are 633 identified species of primates in the world and $54 \%$ of them are threatened, endangered, or critically endangered (IUCN/SSC, 2012). Among them 25 primate species are considered to be the most endangered worldwide (Schwitzer et al., 2015). In Nepal, the estimated current population of Rhesus Macaque is approximately 100,000 and that of Hanuman Langur is not well known (Jnawali et al., 2011).

Parasites are one of the biotic factors which may influence their hosts in different ways (Borgsteede, 1996). Host traits (dominance, sex, age) as well as external conditions such as seasonal changes in temperature, rainfall, resource availability, parasite life-cycles, distance to the nearest town, fragment size, fragment shape and total basal area of food are the factors responsible for parasite infection in wild animals (Valdespino et al., 2010). Parasites affect directly in host survival and reproduction through pathological effects and indirectly by reducing host's physical condition (Kalousova et al., 2014). Severe parasitosis can lead to blood loss, tissue damage, spontaneous abortion, congenital malformations, and death (Despommier et al., 
1995). However, less severe infections are more common and may impair nutrition, travel, feeding, predator escape, and competition for resources or mates, or increase energy expenditure (Packer et al., 2003).

Monkeys are particularly susceptible to parasitic infections because they live in cohesive groups characterized by frequent social interactions (Stoner, 1996) and specific feeding and drinking behavior (Pokhrel \& Maharjan, 2014) which facilitate parasite transmission between individuals. This study was carried out to understand the prevalence of gastro-intestinal parasites in Rhesus Macaque and Hanuman Langur in Devghat, Chitwan and provide baseline data for further action plan.

\section{MATERIALS AND METHODS}

\section{Study site}

Devghat lies in the Central part of Nepal. Its geographical location is $85^{\circ} 22^{\prime} 30^{\prime \prime}$ to $84^{\circ} 30^{\prime} 00^{\prime \prime}$ East longitude and $27^{\circ} 42^{\prime} 30^{\prime \prime}$ to $27^{\circ} 47^{\prime} 30^{\prime \prime}$ North latitude (DADC, 2007). Devghat area is the meeting point of Trishuli and Kaligandaki River as well as three districts, namely Tanahun, Chitwan and Nawalparasi. The study area lies in Bharatpur municipality of Chitwan -01. Site 1 for Rhesus Macaque is located between $84^{\circ} 25^{\prime} 26.82$ " to $84^{\circ} 25^{\prime} 38.86^{\prime \prime}$ East longitude and $27^{\circ} 44^{\prime} 16.27^{\prime \prime}$ to $27^{\circ} 44^{\prime} 26.49^{\prime \prime}$ North latitude and site 2 for Hanuman Langur is located between $84^{\circ} 25^{\prime} 48.21^{\prime \prime}$ to $84^{\circ} 26^{\prime} 53.25^{\prime \prime}$ East longitude and $27^{\circ} 42^{\prime} 54.59^{\prime \prime}$ to $27^{\circ} 43^{\prime} 14.56^{\prime \prime}$ North latitude (Figure 1).

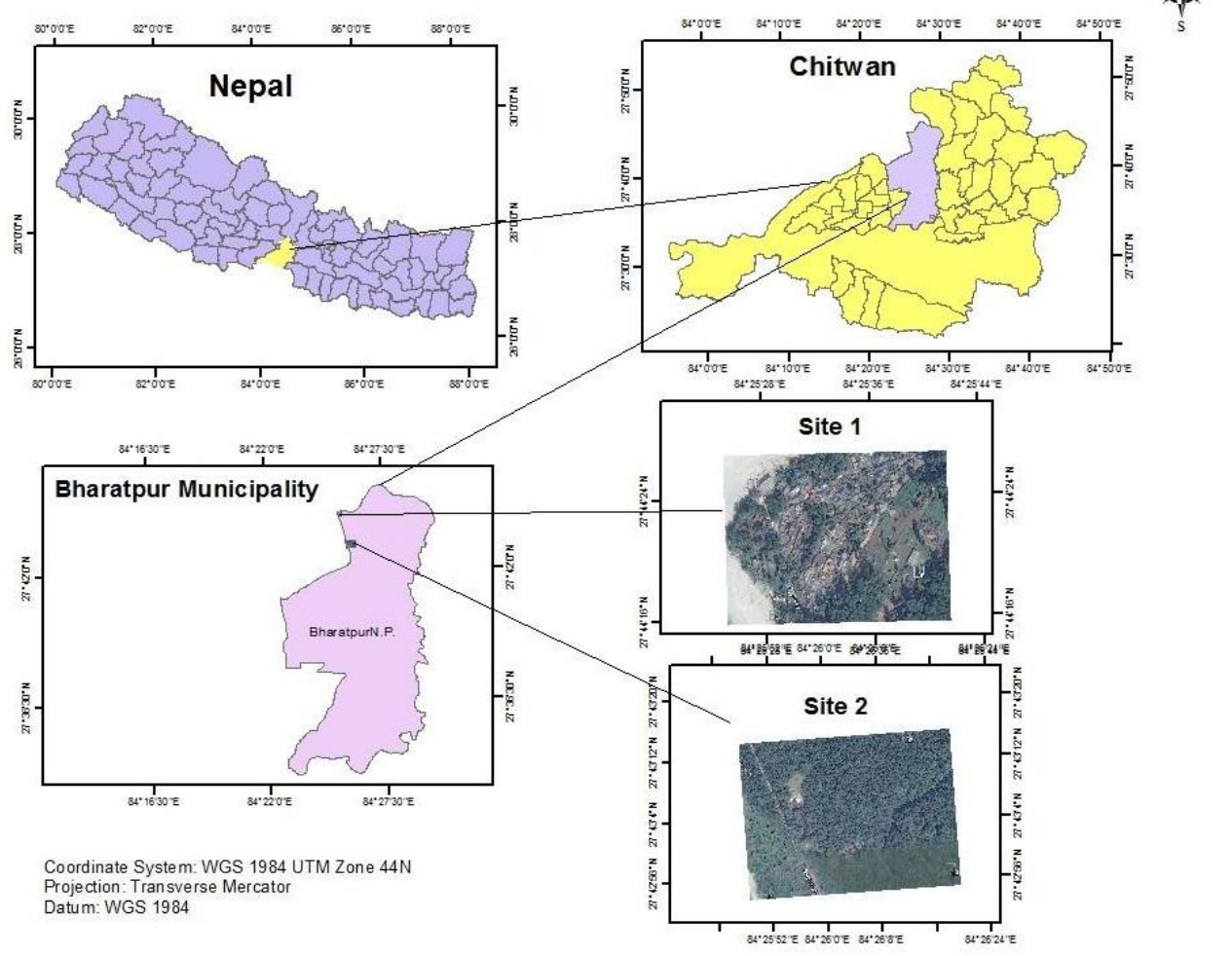

Fig. 1. Study area.

\section{Faecal sample collection and examination}

A total of 93 faecal samples were collected systematically by following the troops of Rhesus Macaque $(n=5)$ and Hanuman Langur $(n=2)$. About 10 gram of faecal material was taken from the faecal mass with the help of wood spoon and placed in a $25 \mathrm{ml}$ vial containing $2.5 \%$ Potassium dichromate solution. The faecal samples were microscopically examined for trophozoites, cysts, oocysts, eggs and larvae of gastrointestinal parasites by concentration methods; floatation technique and sedimentation technique (Soulsby, 1982; Zajac \& Conboy, 2012). Identification of parasites was based on the morphometry of eggs/ cysts under light microscopy (Soulsby, 1982; PV, 2012). By using ocular and stage micrometer, the length, breadth and diameter of parasites (eggs/cysts) were measured with calibration factor. Data were statistically analyzed using Pearson's 
Chi-squared test with Yates' continuity correction, performed by "R", version 3.3.1 software packages.

\section{RESULTS}

Out of 93 fresh feacal samples, 69 (74.20\%) samples were found to be positive for at least one of gastro-intestinal parasites. Prevalence of protozoal infection was $40.86 \%$ and helminth infection was $52.68 \%$ (Figure 2). Prevalence of helminth was higher than protozoa but not significantly different $\left(\chi^{2}=0.884\right.$, df $=1$ and $\mathrm{P}>0.05)$.

\begin{tabular}{|c|c|c|c|c|}
\hline $80.00 \%$ & \multirow[b]{4}{*}{$40.86 \%$} & \multirow[b]{3}{*}{$52.68 \%$} & \multirow[t]{8}{*}{$74.20 \%$} & \multirow{8}{*}{ Positive } \\
\hline $70.00 \%$ & & & & \\
\hline $60.00 \%$ & & & & \\
\hline $50.00 \%$ & & & & \\
\hline $40.00 \%$ & & & & \\
\hline $30.00 \%$ & & & & \\
\hline $20.00 \%$ & & & & \\
\hline \multirow{2}{*}{$\begin{array}{r}10.00 \% \\
0.00 \%\end{array}$} & & & & \\
\hline & Protozoa & Helminth & Total & \\
\hline
\end{tabular}

Fig. 2. Overall prevalence of parasitic infection.

\section{Prevalence of specific gastro-intestinal parasites}

A total of 10 different gastro-intestinal parasites were identified from Rhesus Macaque and Hanuman Langur of Devghat, Chitwan. Identified parasites included three protozoan species (Balantidium coli, Eimeria sp. and Entamoeba sp.) and seven helminth species (Trichuris sp., Ascaris sp., Strongyloides sp., Oesophagostomum sp., Hookworm sp., Trichostrongylus sp. and Hymenolepis sp.).
Among the gastro-intestinal parasites a highest prevalence rate of $27.95 \%$ was detected for Balantidium coli followed by Trichuris sp. (23.65\%), Eimeria sp. (16.12\%), Entamoeba sp. (13.97\%), Ascaris sp. (11.82\%), Strongyloides sp. (10.75\%), Oesophagostomum sp. (5.37\%), Hookworm sp. (3.22\%), Trichostrongylus sp. (3.22\%) and Hymenolepis sp. (1.07\%). Unidentified nematode larvae recorded were $6.45 \%$ of total samples (Figure 3). Overall prevalence of specific GI parasites were highly significance $\left(\chi^{2}=57.987, \mathrm{df}=10\right.$ and $\left.\mathrm{P}<0.05\right)$.

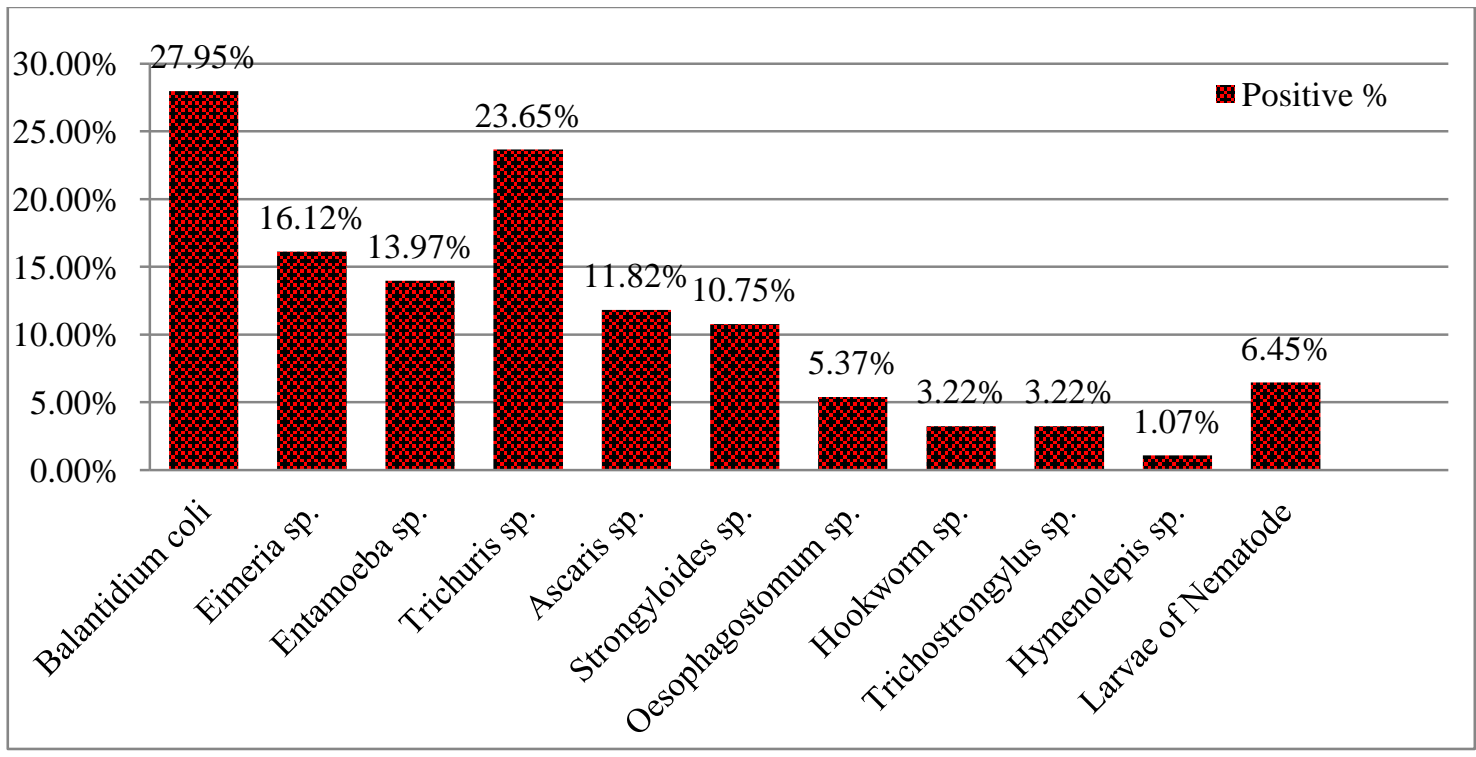

Fig. 3. Prevalence of specific gastro-intestinal parasites. 


\section{Infection status of gastro-intestinal parasites}

The numbers of samples with single, double, triple and more than triple species of parasites was 34, 27,
6 and 2 respectively (Figure 4). The infection status of gastro-intestinal parasites were significantly different $\left(\chi^{2}=38.996, \mathrm{df}=3\right.$ and $\left.\mathrm{P}<0.05\right)$.

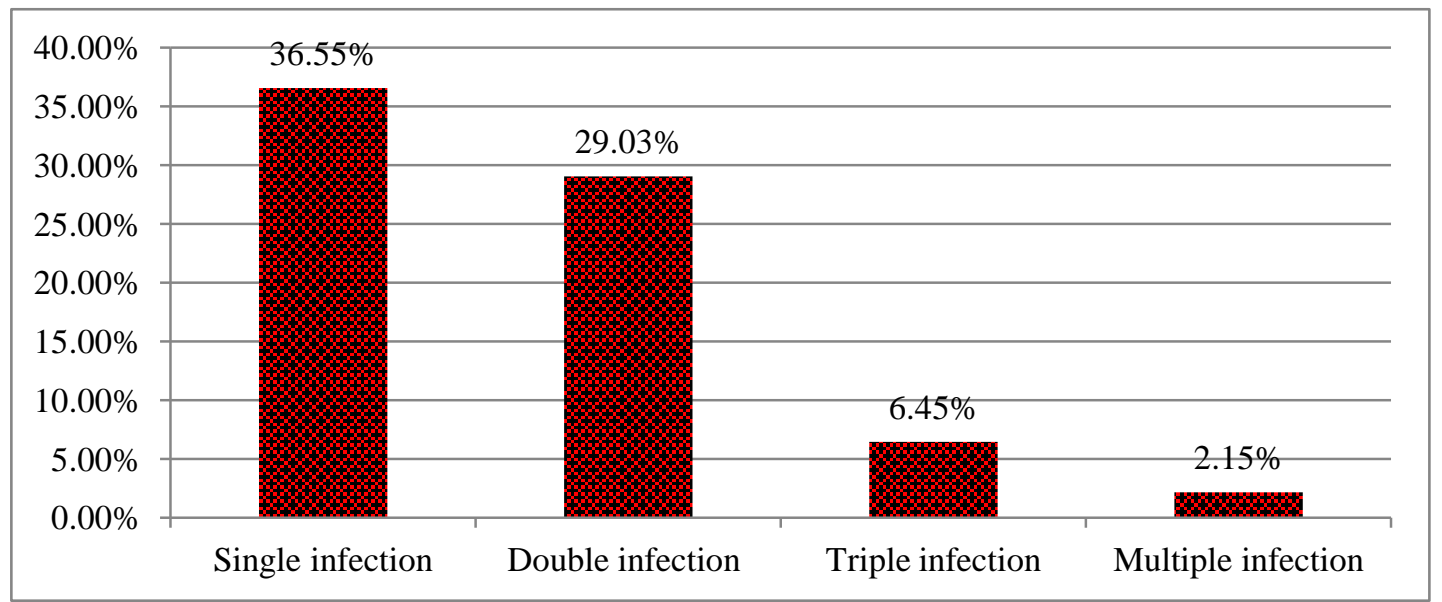

Fig. 4. Infection status of gastro-intestinal parasites.

Prevalence of gastro-intestinal parasites in Rhesus Macaque vs. Hanuman Langur

Among 93 fresh faecal samples, 73 samples were collected from Rhesus Macaque and 20 samples from Hanuman Langur. The prevalence of gastro- intestinal parasite was slightly higher in Rhesus Macaque than in Hanuman Langur (Figure 5), but this difference was not statistically significant $\left(\chi^{2}=0, \mathrm{df}=1\right.$ and $\left.\mathrm{P}>0.05\right)$

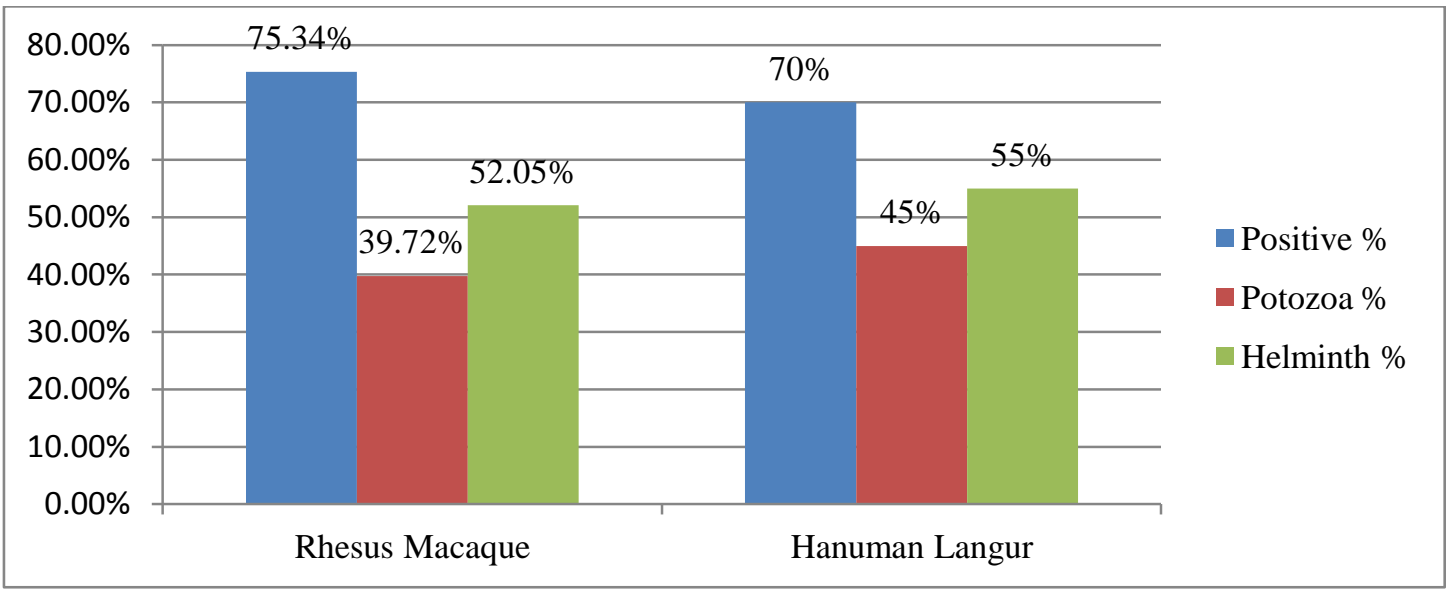

Fig. 5. Prevalence of gastro-intestinal parasites in Rhesus Macaque vs. Hanuman Langur.

\section{DISCUSSION}

In this study, $74.20 \%$ samples were found positive for single or multiple species of parasites. This result is similar to the investigation of Pokhrel and Maharjan (2014) and Jha et al. (2011) who revealed $72.94 \%$ and $76.86 \%$ positive cases from Assamese Macaque and Rhesus Macaque respectively. In case of captive monkeys, the lower rate of prevalence
(Nath et al., 2012) could be due to regular screening of faecal samples and periodical antihelmintic treatment in most of the zoos, as per the protocol of zoo authority.

The prevalence of helminth infection (52.68\%) was found higher than protozoal infection $(40.86 \%)$. Jha et al. (2011) also reported similar result viz. $59.5 \%$ and $53.72 \%$ for helminth and protozoa 
infection respectively. The present study conflict with the report of Hilser et al. (2011) who recorded that $62 \%$ langurs were positive for helminth infection and $82 \%$ were protozoan infection. These differences may be due to geographic condition, source of feeds and feeding behaviour of monkeys.

From the result of current study, three protozoa and seven helminth gastro-intestinal parasites were reported from Rhesus Macaque and Hanuman Langur. In protozoa, Balantidium coli was found in maximum positive samples ie. $27.95 \%$, this supports the findings of Pokhrel and Maharjan (2014) and Jha et al. (2011) from Assamensis Monkeys and Rhesus Monkey respectively. It has a wide host range and possess a simple direct life cycle and it's occurrence in primates has been previously confirmed by Lim et al. (2008) and Khatun et al. (2014). From the present study, other protozoa such as Eimeria sp. and Entamoeba sp. were found to be $16.12 \%$ and $13.97 \%$ respectively. In helminth, Trichuris sp. showed the higher prevalence rate than other parasite ie., $23.65 \%$. This type of result also supported by Pokhrel and Maharjan (2014) from Assamese Macaque, by Huffman et al. (2013) from Macaca sp. and langur monkeys, by Nath et al. (2012) from Macaca sp. and Golden Langur, by Hilser et al. (2011) from Red Langursand, by Parmar et al. (2012) from Hanuman Langur. The high prevalence rate of Trichuris sp. might be due to climatic condition because Trichuris sp. well exist in a warm moist climate, low light, wet soil within temperate and tropical climates (Roberts \& Janovy, 2000). The present study area (Devghat, Chitwan) is a lowland and frequently wet due to the Narayani River with Tropical forest. The percentage of Ascaris sp. in the present study was found to be $11.82 \%$. This is also confirmed from Red Langur (Hilser et al., 2011), Hanuman Langur and Rhesus Macaque (Parmar et al., 2012) and Assamese Macaque (Pokhrel \& Maharjan 2014). But Arunachalam et al. (2015) documented it to be $5 \%$. The overall infection of Strongyloides sp. was $10.75 \%$. It is supported by Hilser et al. (2011) from Red Langur, and by Pokhrel and Maharjan (2014) from Assamese Macaque. But, Parmar et al. (2012) showed higher prevalence $(26.66 \%)$ from Hanuman Langur. Oesophagostomum sp. infection account for $5.37 \%$ of total samples. It has been reported from Assamese Monkey, Golden Langur, Rhesus Monkey, Presbytis sp. (Dewit et al., 1991; Nath et al., 2012; Thawait et al., 2014; Pokhrel and Maharjan, 2014). Previous results ranged from $4 \%$ -
$28 \%$ but Dewit et al. (1991) recorded 80\% prevalence of Oesophagostomum sp. Hookworm sp. was found in $3.22 \%$ in present study. It is similar to the reports of Pokhrel and Maharjan (2014) with $4.7 \%$ and contrary to the result of Hilser et al. (2011) and Mutani et al. (2003) with $8 \%$ and $34 \%$ respectively. Soil moisture, sanitary condition of environment and climatic condition are important factors describing the differences of prevalence rates of parasite species among various geographical areas (Nunn et al., 2005). Prevalence of Trichostrongylus sp. was found to be $3.22 \%$ among the helminth parasites. This result was supported by Hilser et al. (2011) from Red Langur. The prevalence of these parasites in monkey is interesting because it is an important parasite of ruminants (grazing mammals) (Crockett \& Dipeolu, 1984). Therefore, prevalence of parasites can be due to contamination of their environment with ruminant waste. The present study revealed Hymenolepis sp. as the least common parasite with $1.07 \%$ prevalence. It has been reported from Macca sinica and Presbytis sp. (Dewit et al., 1991), Capped Langur (Sing et al., 2009) and Drill Monkey (Akpan et al., 2010). It is a common parasite of rodents with beetle and fleas as intermediate host. Due to the insectivorous nature of monkey or accidental ingestion of fleas, they are likely to be infected.

The huge diversity and densities of parasites represent enormous diversities of life cycle, transmission routes and pathogenicity that cause significant harm to animals. Heavy parasite infestation affects wild life severely and can be a threat to conservation (Woolhouse, 2002). Multiple infections are more harmful than single infection. Multiple infections may cause heavy losses through impact on growth pattern, reproduction, fecundity and establishment along with being the cause of death. Monkeys with multiple parasitic infections are at higher risk if untreated.

\section{CONCLUSION}

It is concluded that, the monkeys of Devghat, Chitwan are infected with various protozoa and helminth gastro-intestinal parasites. Among the protozoal infection Balantidium coli was highly prevalent compared to other parasites such as Eimeria sp. and Entamoeba sp. Among the helminth infection Trichuris sp. was found to be highly prevalent than other parasties such as Ascaris sp., Strongyloides sp., Oesophagostomum sp., Hookworm sp. Trichostrongylus sp. and 
Hymenolepis sp. Among the parasitic infection $2.15 \%$ monkeys are at high risk to critical infection of gastro-intestinal parasites because they were found to have multiple infections.

\section{ACKNOWLEDGEMENTS}

We would like to express our gratitude to the Devghat Area Development Committee for giving permission to conduct the research work in such area. In addition, we also extent thanks to Central Department of Zoology for proving laboratory facilities. We are also grateful to Mr. Bikash Baral, Mr. Pradip Subedi and Mr. Prashanta Adhikari for their precious help during research work. Our thanks and appreciations to all the teachers, staff and associated persons. Last but not least, we are thankful to Mr. Jaya Ram Adhikari for helpful comments while preparing this manuscript.

\section{REFERENCES}

Akpan, P. A.; Abraham, J. J. and Ekwetiong, P. O. (2010). Survey of gastro-intestinal parasites of Chimpanzees and Drill Monkeys in Drill Ranch, Calabar, Cross River State-Nigeria. An International Multi-Disciplinary Journal, Ethiopia, 4 (3a): 334-350.

Arunachalam, K.; Senthilvel, K. and Anbarasi, P. (2015). Endo parasitic infections in free living Rhesus Macaque (Macaca mulatta) of Namakkal, Tamil Nadu, India. Department of Veterinary Parasitology, Veterinary College and Research Institute, Namakkal, Tamil Nadu. ZOO's PRINT, Volume XXX.

Borgsteede, F. H. M. (1996). The effect of parasites on wildlife. Veterinary Quarterly, 18 (3): 138-140.

Chalise, M. K.; Karki, J. B. and Ghimire, M. K. (2005). Status of non-human primate biodiversity efforts in Nepal. Department of National Park and Wildlife Conservation /HMG Nepal, pp. 19-26.

Crockett, E. C. and Dipeolu, O. O. (1984). A survey of helminth parasites of game animals in Kainji Lake National Park of Nigeria. International Journal of Zoonoses, 11: 204-215.

DADC (2007). Master plan of Devghat area. Government of Nepal, Ministry of Federal Affairs, Constitute Assembly, Parliamentary Affairs and Culture, Devghat Area Development Committee, Devghat Tanahun.
Despommier, D. D.; Gwazda, R. W. and Hotez, P. J. (1995). Parasitic diseases, springer-Verlag, New York.

Dewit, I.; Dittus, W. P. J.; Vercruysse, J.; Harris, E. A. and Gibson, D. I. (1991). Helminths in a natural population of Macaca sinica and Presbytis spp. at Polonnaruwa, Sri Lanka. Primates, 32 (3): 391-395.

Gewali, M. B. (2013). Bioprospecting in: Environment and Natural Resources. Jha, P. K., Neupane, F. P, Shrestha, M. L. and Khanal, I. P. (eds). Nepal Academy of Science and Technology, Khumaltar, Lalitpur, pp. 162-166.

Hilser, B. H.; Cheyne, S. M. and Ehlers-Smith, A. D. (2011). Socioecology and gastro-intestinal parasites of sympatric primate species inhabiting the Sabangau Peat-Swamp Forest, Central Kalimantan. American Journal of Primatology, 74: 31-49.

Huffman, M. A.; Nahallage, C. A. D.; Hasegawa, H.; Ekanayake, S.; De-Silva, L. D. G. G and Athauda, I. R. K. (2013). Preliminary survey of the distribution of four potentially zoonotic parasite species among primates in Sri Lanka. J. Natn. Sci. Foundation, Sri Lanka, 41 (4): 319-326.

IUCN/SSC (2012). Red data book and species survival committee, primate specialist group, primates in Peril: The world's 25 most endangered primates.

Jha, A.; Chalise, M. K.; Shrestha, R. M. and Karki, K. (2011). Intestinal parasitic investigation in temple Rhesus Monkeys of Kathmandu. SUFFREC. The Initiation, 4: 1-7.

Jnawali, S. R.; Baral, H. S.; Lee, S.; Acharya, K. P., Upadhyay, G. P., Pandey, M. et al. (2011) (Compilers).The status of Nepal's mammals: The national red list series, Department of National Parks and Wildlife Conservation, Kathmandu, Nepal.

Kalousova, B.; Piel, A. K.; Pomajbikova, K.; Modry, D.; Stewart, F. A. and Petrzelkova, K. J. (2014). Gastrointestinal Parasites of Savanna Chimpanzees (Pan troglodytes schweinfurthii) in Ugalla, Tanzania. Int J. Primatol, Springer Science+Business Media New York.

Khatun, M. M.; Begum, N.; Mamun, M. A. A.; Mondal, M. M. H. and Shakif-Ul-Azam, M. M. (2014). Coprological study of gastrointestinal parasites of captive animals 
at Rangpur Recreational Garden and Zoo in Bangladesh. Journal of Threatened Taxa, 6 (8): 6142-6147.

Lim, Y. A. L.; Ngui, R.; Shukri, J.; Rohela, M. and Mat, N. H. R. (2008). Intestinal parasites in various animals at a zoo in Malaysia. Veterinary Parasitology, 1(57): 154-159.

Mutani, A.; Rhynd, K. and Brown, G. (2003). A preliminary investigation on the gastrointestinal helminthes of the Barbados Green Monkey (Cercopithecus aethiops sabaeus). Rev. Inst. Med. trop. S. Paulo, 45 (4): 193-195.

Nath, B. G.; Islam, S. and Chakraborty, A. (2012). Prevalence of parasitic infection in captive non-human primates of Assam State Zoo, India. Vet World, 5 (10): 614-616.

Nunn, C. L.; Altizer, S. M.; Sechrest, W. and Cunningham, A. A. (2005). Latitudinal gradients of parasite species richness in primates. Divers. Distrib. 11: 249-256.

Packer, C.; Holt, R. D.; Hudson, P. J.; Lafferty, K. D. and Dobson, A. P. (2003). Keeping the herds healthy and alert: implications of predator control for infectious disease. Ecol. Lett., 6: 1-6.

Parmar, S. M.; Jani, R. G. and Mathakiya, R. A. (2012). Study of parasitic infections in nonhuman primates of Gujarat state, India, Vet. World, 5 (6): 362-364.

Pokhrel, G. and Maharjan, M. (2014). Gastrointestinal parasites of Assamese Macaque (Macaca assamensis Hodgson, 1840) in Shivapuri Nagarjun National Park. Journal of Institute of Science and Technology, 19 (2): 53-57.

PV (2015). Veterinary parasitology. The practical veterinarian, pp. 77-319.

Roberts, L. and Janovy, J. (2000). Foundations of Parasitology. New York: McGraw Hill.

Schwitzer, C.; Mittermeier, R. A.; Rylands, A. B.; Chiozza, F.; Williamson, E. A.; Wallis, J. and Cotton, A. (eds.) (2015). Primates in peril: the world's 25 most endangered primates 2014-2016. IUCN SSC primate specialist group (PSG), International Primatological Society (IPS), Conservation International (CI), and Bristol Zoological Society, Arlington, VA.
Singh, P.; Singla, L. D.; Gupta, M. P.; Sharma, S. and Sharma, D. R. (2009). Epidemiology and chemotherapy of parasitic infections in wild omnivores in the Mahendra Choudhury Zoological Park, Chhat Bir, Punjab. Journal of Threatened Taxa, 1 (1): 62-64.

Soulsby, E. J. L. (1982). Helminthes, arthropods and protozoa of domesticated animals (seven edition). The english language book society and baillieretinadall, London.

Stoner, K. and Gonzalezdi-Pierro, A. M. (2006). Intestinal parasitic infections in Alouatta pigra in tropical rainforest in Lacandona, Chiapas, Mexico: Implications for behavioral ecology and conservation. In: Estrada, A.; Garber, P. A.; Pavelka, M.; Luecke, L. eds. New perspectives in the study of mesoamerican primates: distribution, ecology and conservation. USA: Springer, pp. 215240.

Thawait, V. K.; Maiti, S. K. and Dixit, A. A. (2014). Prevalence of gastro-intestinal parasites in captive wild animals of Nandan Van Zoo, Raipur, Chhattisgarh. Veterinary World, 7 (7): 448-451.

Valdespino, C.; Rico-Hernandez, G. and Mandujano, S. (2010). Gastrointestinal parasites of Howler Monkeys (Alouatta palliate) inhabiting the fragmented landscape of the Santa Marta Mountain Range, Veracruz, Mexico. American Journal of Primatology, 71: 1-10.

Woolhouse, M. E. J. (2002). Population biology of emerging and re-emerging pathogens. Trends in Microbiology, 10 (10).

Zajac, A. M. and Conboy, G. A. (2012). Veterinary clinical parasitology. Eighth edition. American Association of Veterinary Parasitologist. Blackwell publishing, Oxford, U. K. 